\title{
Management of multi-source information to identify the typology of the horizontal structures in historical masonry buildings: the case study of the Museum of Capodimonte in Naples (Italy)
}

\author{
A. Maione, L.U. Argiento, C. Casapulla, A. Prota \\ University of Napoli Federico II, Department of Structures for Engineering and Architecture \\ arch.maione@gmail.com,lucaumberto.argiento@unina.it,casacla@unina.it,.aprota@unina.it
}

\begin{abstract}
The evaluation of the seismic safety of ancient masonry buildings usually requires compounding the need of preservation of the historical values with the need of achieving a proper level of knowledge of the parameters influencing their structural behaviour. To this aim, non-destructive techniques of instrumental investigation have lately attracted increasing attention, although the provided data are frequently not exhaustive and require to be integrated with different sources of information, such as historical documents and hypotheses of critical interpretation. Therefore, the management of this multi-source information is a crucial aspect in defining a methodological approach to the structural evaluation of the cultural heritage. This paper describes an integrated approach developed in the framework of the Project on the seismic evaluation of the Museum of Capodimonte in Naples (Italy) with reference to the typological identification of the horizontal structures upon the first level of the building. The management of the data derived from the application of the infrared thermography, integrated with the information from the visual inspections, the architectural survey and the historic analysis, has allowed obtaining a complete characterization of the structures under study.
\end{abstract}

KEYwORDS. Masonry vaults; Historical buildings; Integrated Methodological approach; Non-Destructive Testing (NDT) methodologies.

\section{OPEN $\bigcirc$ ACCESS}

Citation: Maione, A., Argiento, L.U., Casapulla, C., Prota A, Management of multisource information to identify the typology of the horizontal structures in ancient masonry buildings: the case study of the Museum of Capodimonte in Naples (Italy), Frattura ed Integrità Strutturale, 46 (2018) 240-251.

Received: 29.07.2018

Accepted: 02.09.2018

Published: 01.10.2018

Copyright: (C) 2018 This is an open access article under the terms of the CC-BY 4.0, which permits unrestricted use, distribution, and reproduction in any medium, provided the original author and source are credited.

\section{INTRODUCTION}

$\mathrm{T}$ he evaluation of the seismic safety of ancient masonry buildings requires the acquisition of an adequate knowledge about their main structural features in order to define a reliable model of the seismic behaviour. To this aim, Italian guidelines and European projects $[1,2]$ have recently provided useful suggestions to address this preliminary phase of investigation, highlighting the main aspects which have to be focused; they concern the geometry of 
the resistant elements, the constructive typology, the state of conservation, material degradation and mechanical properties together with a proper knowledge about the foundation soil and the possible interaction with adjacent buildings. In this phase an integrated approach is crucial to critically manage multi-source information provided by visual inspections, historical documents and instrumental investigations [3]. An interesting experimentation of such an approach has been carried out by the authors in the framework of the Italian ARCUS-MiBACT Project on the "Assessment of the seismic safety of National Museums of Italy" [4] supported by the Ministry of the Cultural Heritage (MiBACT). The project, aimed at assessing the seismic safety of a historic masonry building [5, 6], and applied to the Capodimonte Museum in Napoli (Fig. 1) and to other National museums, has been developed according to the Italian Guidelines on Cultural Heritage [1]. In particular, this paper is focused on the approach developed by the authors to achieve a proper characterization of the constructive features of the horizontal structures upon the first level of the Museum, most of them strongly modified in the '50s of the last century to host the exposition of the painting collection of the Museum [7]. It is well known in fact, also on the basis of the recognition of seismic damage, that the horizontal structures strongly influence the seismic behaviour of masonry buildings. This is due to their properties of mass and stiffness which affect the entity and the repartition of the seismic forces among the vertical walls, while the effectiveness of their connection with the vertical structures ensures the occurrence of a global behaviour preventing the out-of-plane mechanisms of the walls [811]. Besides, this effectiveness has the same importance even for other structural typologies of buildings, e.g. timber and r.c. systems $[12,13]$.

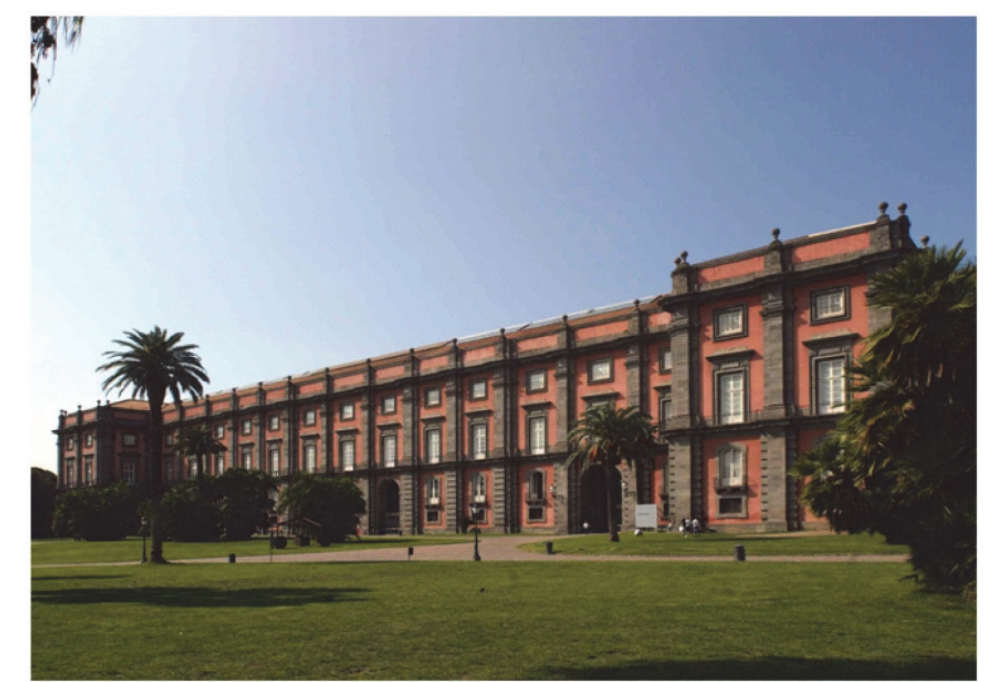

Figure 1: External view from east side of the Capodimonte Museum.

Hence, the identification of the constructive typology of the horizontal structures is a crucial aspect in defining proper models of the seismic behaviour of masonry buildings and can also help to optimize energy and structural aspects in retrofitting [14]. However, when cultural heritage buildings are involved, some difficulties can arise in the acquisition of the data required by a proper characterization of these structures. In these cases, in fact, the execution of direct inspections and testing is usually not compatible with the needs to preserve the historical and artistic values inherent to painted ceilings or remarkable floors, while other difficulties can be related to the possibility to access these structures safely. To this aim, non-destructive testing (NDT) methodologies have lately gained increasing interest, mainly due to the continuous improvement of technologies characterized by a low impact on the structures [15-20].

In particular, for the presented case study, the lack of clear information concerning the renewal of the spaces on the first level, arranged for the new museum use [7], was another reason for providing a diagnostic investigation plan. Infrared thermography proved to be a useful method to answer critical questions related to the interpretation of the structural role of some vaults and also to overcome the difficulty to approach these structures; mostly the use of a scaffolding to go hand knocking on their intrados and listening the acoustic vibrations is generally not allowed in such places hosting museums because of the risks for the precious contents. Infrared thermography, instead, does not require contact with the tested object and allows preserving its integrity [21-23] and it seems to be very promising in order to obtain also quantitative data thanks to the recent advances in thermographic signal processing. This technique is usually carried out according to two distinct approaches depending on the existing thermal contrast between the investigated object and the background. The passive approach detects the thermal radiation emitted by its surface under natural conditions, without employing any 
heating; this approach provides mainly qualitative data about the object. The active approach, instead, requires artificial heating usually obtained with the light emitted by flashed lamps, lasers or other light sources. Maierhofer and Roellig [24] presented several case studies showing the effectiveness of the impulse-thermography for the investigation of cracks, delaminations and masonry structure behind plaster. Both active and passive approaches were recently adopted by Cantini et al. [25] in the study of the vault of the Assembly Room within the Palace of the Academy of Sciences in Torino; the active approach allowed detecting the presence of detached areas of the stuccowork, while the passive approach was used for the identification of the structural elements of the wooden frame of the vault.

The passive approach has been used for the investigation of some vaulted structures in the Capodimonte Museum, as described in this paper, and the qualitative information obtained on their constructive typology have been interpreted and coordinated with other sources of information; such integrated approach has allowed achieving a proper characterization of the constructive features of the horizontal structures upon the first level of the Museum.

Hence, in the following sections, the case study is firstly presented highlighting the critical issues raised from a first step of visual inspection; then the findings of the thermographic survey are presented together with short references to the basic principles of this technique. Finally the instrumental findings have been interpreted and integrated with other sources of information providing a classification of the analysed horizontal structures that has been useful for the definition of a proper model of the building to evaluate its seismic safety. Only the results of the visual inspections and thermographic survey together with the discussion on the critical issues are presented in this paper, while more details on historical analysis, geometrical/architectural survey and damage inspections can be found in [4].

\section{THE CASE STUdy OF THE CAPODIMONTE MUSEUM IN NAPLES: CRITICAL ISSUES}

7 he case study analyzed in this paper may assume a paradigmatic relevance in drawing up an integrated approach to the identification of the structural features of ancient masonry buildings. In particular, the attention is focused on the horizontal structures covering the rooms on the first level of the Capodimonte Museum. These rooms were originally meant to royal apartment, but in the '50s of the last century they were transformed according to the project of the architect De Felice to host the exposition of the painting collection of the Museum [7]. The available documentation of the project, however, shows that it was aimed at preserving the historical asset of the rooms by adopting architectonical solutions that try to simulate the aspect of the ancient structures, as will be confirmed by the instrumental investigations described in the following section.

According to the Italian Guidelines [1], a basic level of knowledge was firstly achieved through the visual inspections and the architectural survey; these activities together with the verification of the data derived from the documentary and bibliographic sources allowed identifying the essential geometrical and constructive features of the building, as described in detail in [4]. However, at the end of this first phase of knowledge some problematic aspects arose, requiring deeper investigations. They mainly concern the characterization of the constructive typology of three couples of adjacent rooms, characterized by a similar configuration and indicated with the numbers 9 and 49,10 and 48, 11 and 47 in the plan layout of the first floor (Fig. 2a). The vaults of these rooms are a type rather common in Italy known as a schifo or mirror vault, and two of them are painted vaults (no. 9 and 10 in Fig. 2b and 2c, respectively); all of them, however, are supported by structural masonry walls on three sides, while on the fourth side there is only a thin wall of about $20 \mathrm{~cm}$ which divides the adjacent rooms. This configuration can also be found in other rooms, such as 17, 18, 33 and 53 in Fig. 2a, while the mirror vaults covering most of the rooms on the first level are conventionally supported, even if not in all cases with loadbearing function. The two large and double height rooms at the north-eastern and south-eastern corners are covered by cloister vaults overlaid by r.c. structures, while other mixed and overlapped typologies are present on the other rooms, as investigated and described later in the text.

Hence, in order to understand whether the vaults of adjacent rooms have decorative or structural function, the following hypotheses were formulated on the basis of the critical analysis of the historical documentation and of the geometrical survey [4].

According to a first hypothesis, the two adjacent rooms derive from the partition of a unique space covered by a structural masonry vault, maybe required by the exhibition needs of the Museum. With this transformation, three sides of the original vault were preserved, while a wooden structure was built on the fourth one, resembling the profile of the vault. This hypothesis is supported by the inclination of the fourth side of the vault that appears considerably more pronounced. Another possible hypothesis is that the present visible vaults are not load-bearing, but they have a timber structure that repeats the shape of the original masonry vault. This kind of solution, on the other hand, was found out in the rooms 51 and 52 (see Fig. 3) which also result from the division of a unique space; in fact, by approaching the narrow space behind 
the room 52 (hosting the precious "Salottino di porcellana") it was possible to discover that under the original masonry vault, still in place, there was a timber structure consisting in a series of ribs completed with a mat of plaited canes and bricks on a sheet. The height at the keystone of this latter vault is lower than that of the original one.

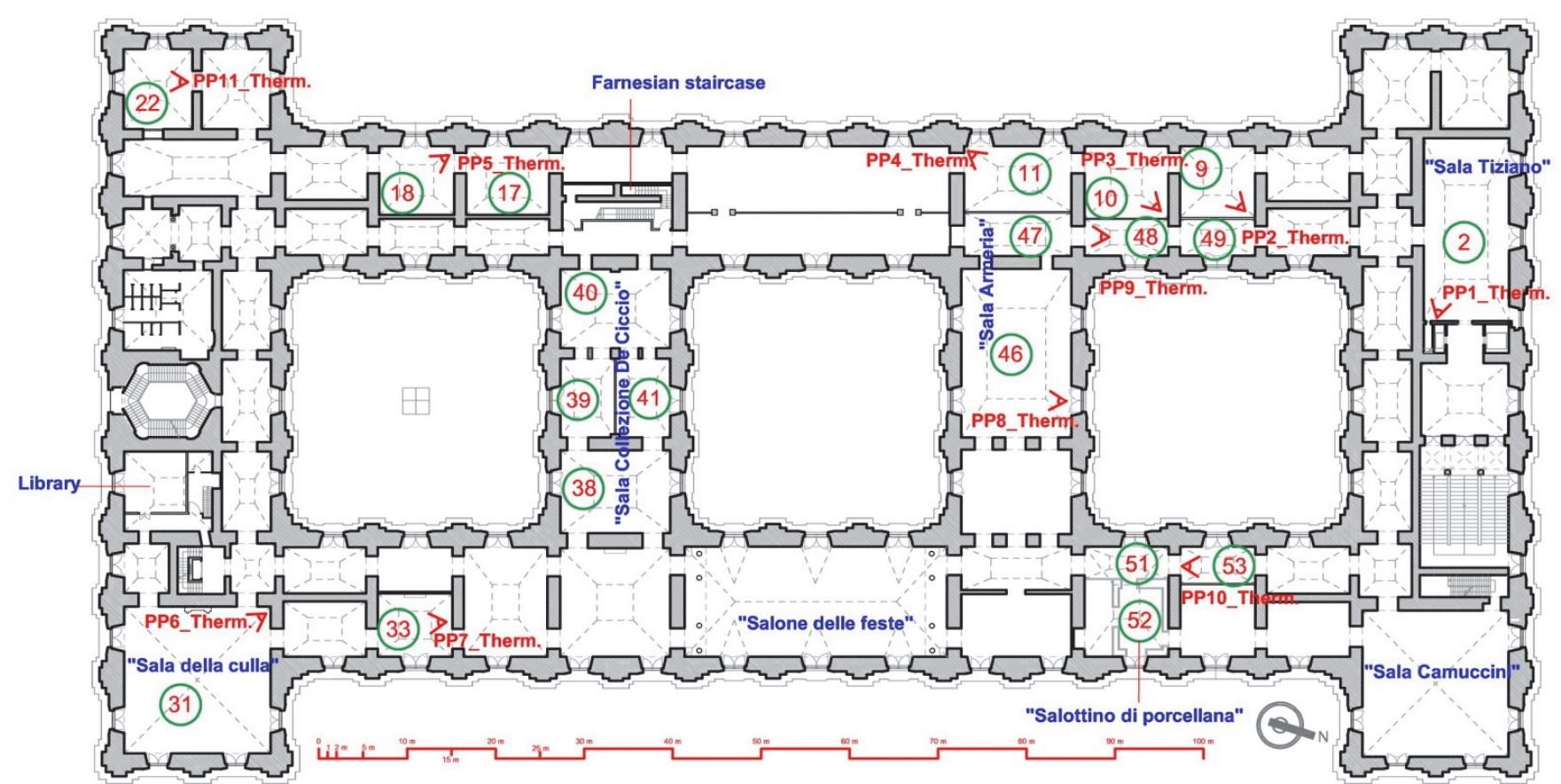

(a)

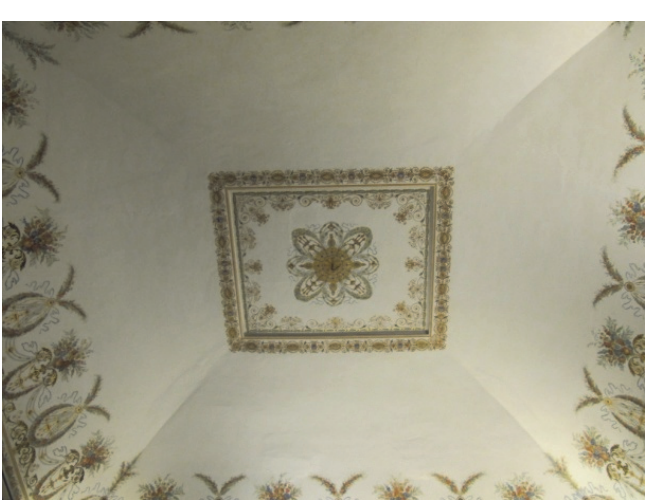

(b)

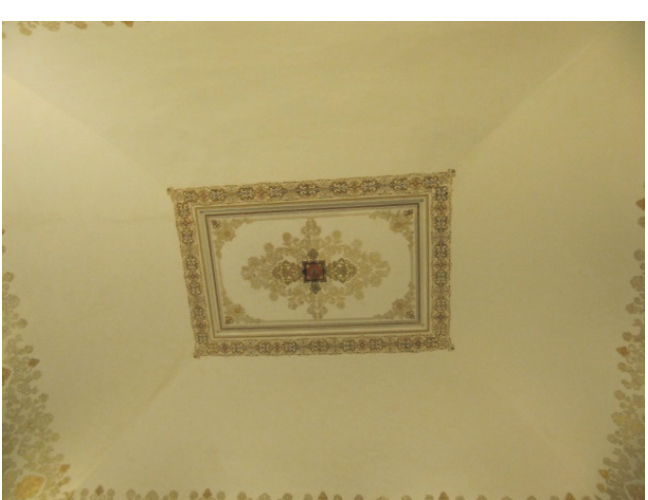

(c)

Figure 2: (a) Planimetric identification of the three couples of adjacent rooms ( 9 and 49, 10 and 48, 11 and 47); views of the intrados of the painted vaults related to (b) room 9 and (c) room 10.

Hence, it was supposed that a similar solution had been adopted for the rooms under study. In this case, the problem was also to understand whether the original vaulted structure was still in place or was replaced by a concrete slab.

Lastly, a third hypothesis assumes that the present visible vaults are structural masonry vaults but their fourth side, corresponding to the thin wall, is carried out by a concrete curb.

In order to verify the formulated hypotheses a diagnostic strategy was defined with the objective of finding a compromise between the need of preserving the historical value and the public function of the building on one side, and the need of modelling the structural behaviour on the basis of a satisfactory knowledge of the constructive details, on the other side. The non-destructive technique of the infrared thermography was chosen to this aim. The diagnostic campaign was performed by the Stress-scarl district, Consorzio Tre and the Testing Laboratory collaborating with the Dist Department of the University of Naples (Italy). 


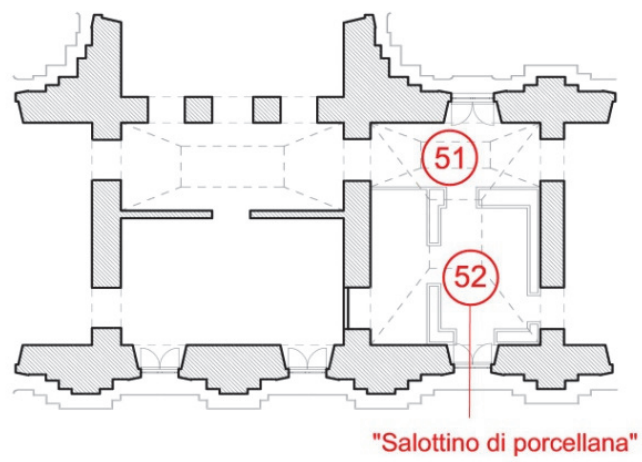

(a)

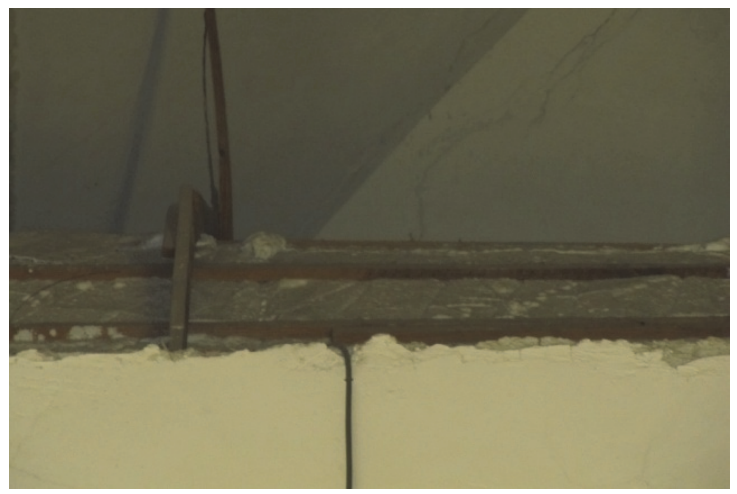

(b)

Figure 3: "Salottino di Porcellana" (room 52): (a) planimetric position and (b) timber vault realized under the earlier masonry vault, visible from the empty space behind the room.

\section{THE INSTRUMENTAL INVESTIGATIONS}

\section{Basic theoretical principles of the infrared thermography}

7 he thermographic surveys were carried out using an infrared camera (thermal camera) that allows detecting infrared energy emitted from an object, converting it into apparent temperature, and displaying the result as an infrared image. In fact, all elements with a temperature above absolute zero emit heat and therefore radiation in the infrared field.

The thermal or infrared energy is characterized by a wavelength too large to be visible; it is, in fact, the portion of the electromagnetic spectrum that is perceived as heat. Thereafter the infrared cameras operate in wavelengths as long as $14000 \mathrm{~nm}(14 \mu \mathrm{m})$ while common cameras, forming images using visible light, operate in the range of 400-700 nanometres.

The existence of the infrared radiation was discovered in the $19^{\text {th }}$ century by William Herschel [26]. He used a prism to produce a spectrum of colours and noticed that the temperatures of the colours increased from the violet to the red part of the spectrum. He also found that the highest temperatures are beyond the red portion of the spectrum in a region where no sunlight is visible.

The functional principle of the infrared thermography is governed by three essential physical laws [27]:

- Kirchboff's law defines the relation between emission and absorption of energy, which states that the absorption of a body has to equal its emissivity at every wavelength;

- Planck's law of radiation describes the distribution of the amplitudes of the energy that a black-body emits as radiation vs. different frequencies or wavelengths (i.e. spectral radiance);

- Stefan-Boltzmann law is applied to the emission of a surface over all wavelengths and states that the radiant power, I, grows with the fourth power of its absolute temperature.

The results of the infrared thermography are influenced by three essential factors: the surface configuration, the surface roughness and the environmental conditions.

The surface configuration influences the thermal conductivity that can be reduced if air voids and low density areas are present.

The surface roughness has the effect of increasing the surface emissivity with respect to that related to a smooth surface. This parameter is strictly related to the material characterizing the surface.

The environmental conditions such as solar exposition, temperature, wind speed, surface moisture that surrounds the surface affects the validity of the image interpretation.

\section{The application of the infrared thermography to the case study}

For the thermographic investigations into the Capodimonte Museum the ThermaCAM B640 model of the FLIR Company was used. The system is provided with a Focal Plane Array detector operating in the band 7.5-13 lm and detects a temperature range from $-40^{\circ} \mathrm{C}$ to $+120^{\circ} \mathrm{C}$ with a measurement accuracy of $\pm 2^{\circ} \mathrm{C}$. A passive approach of investigation was adopted by using the natural heat sources of the building as the solar radiation or the slow microclimate temperature. 
In order to test the sensitivity of the camera, a preliminary thermographic scan of the vault covering the room 2 called "Sala Tiziano" was carried out (Fig. 4). Here the presence of a timber structure was considered very likely because the arrangement of this area together with the Auditorium on the ground floor can be dated back to 1950s; in that period the pre-existing Royal Chapel, that developed with its height along two levels, was completely transformed with the creation of an intermediate floor in order to ensure the continuity of the expositive path [7]. Then this supposition was confirmed by the thermography as shown in Fig. 4c.

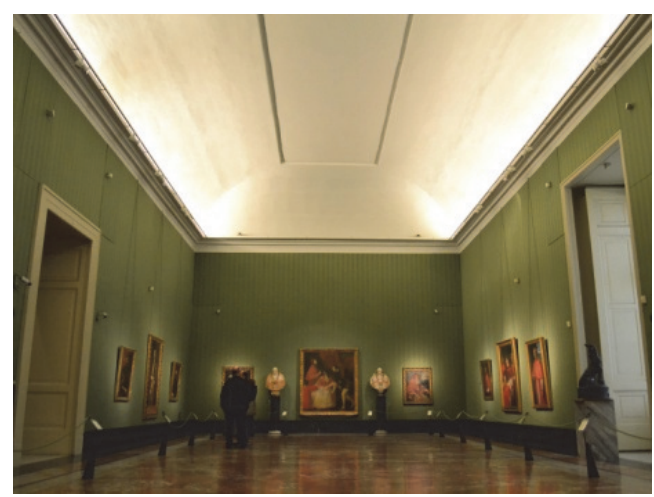

(a)

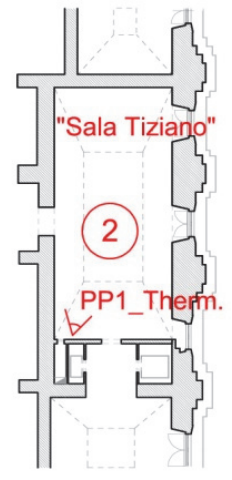

(b)

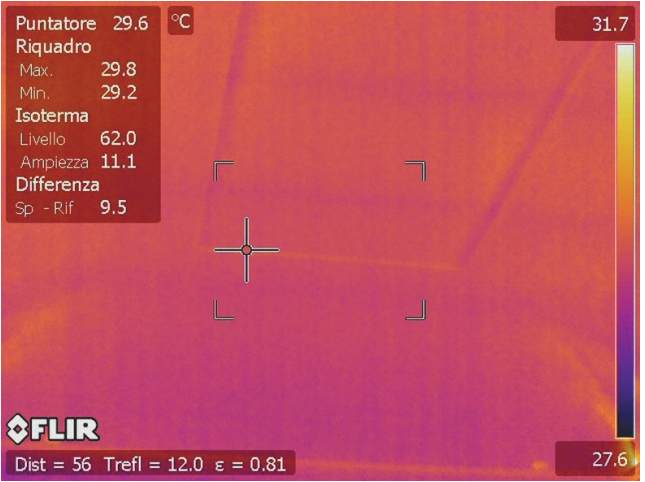

(c)

Figure 4: Room 2 "Sala Tiziano": (a) perspective view, (b) planimetric localization of the point of view of the camera and (c) thermographic image of the intrados of the vault.

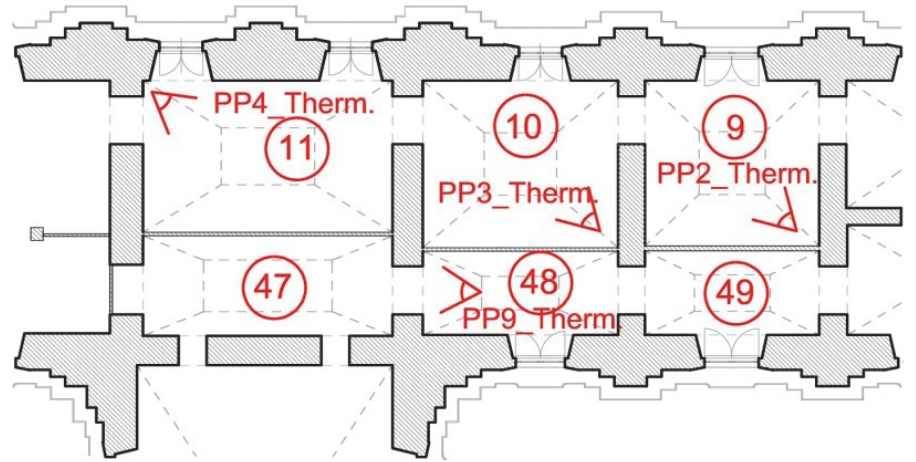

(a)

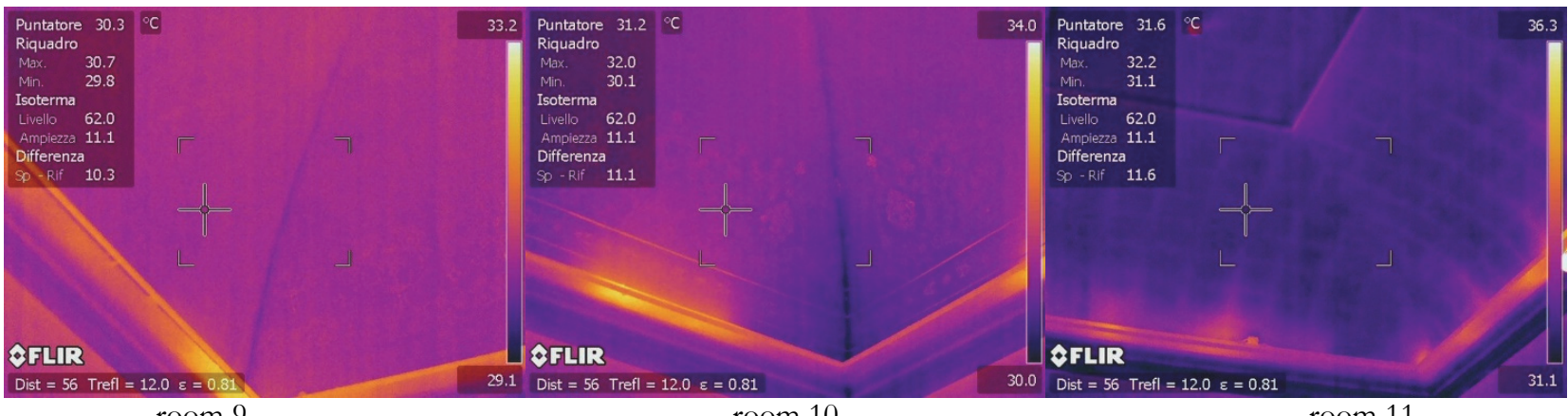

room 9

room 10

room 11

Figure 5: Planimetric localization of the points of view of the camera (a) and thermographic images of the intrados of the vaults for rooms 9, 10 and 11.

Fig. 5 reports the results of the thermographic survey related to the vaults covering the rooms 9, 10 (both painted) and 11 . In particular, the thermographic image related to room 11 confirmed that it is not structural, as already suggested by the presence of a thin wall in common with the adjacent room 47. 
On the other hand, also the vault covering the room 47 has probably a timber structure, as suggested by the thermographic image of the similar room 48 in Fig. 6b. It is very likely, therefore, that the timber structures were created after the partition of the unique space covered by the original vault.

Instead, as far as the painted vaults of the rooms 9 and 10 are concerned, their thermographic images do not reveal the signs of the timber skeleton and this may led to suppose the presence of masonry vaults. This result, however, seems to be not consistent with the presence of a non-structural wall on one side, as previously highlighted.

Thus, a plausible explanation of this configuration was derived from a further typology of vault (Fig. 7) that was possible to see from a crawl space of the Farnesian staircase. It is a no-load-bearing masonry vault, characterized by a thin thickness of bricks disposed on a sheet $(20 \mathrm{~cm}$ average thickness). This typology could be compatible with the underneath thin wall and maybe it was related to the need of preserving the paintings on their intrados surface.

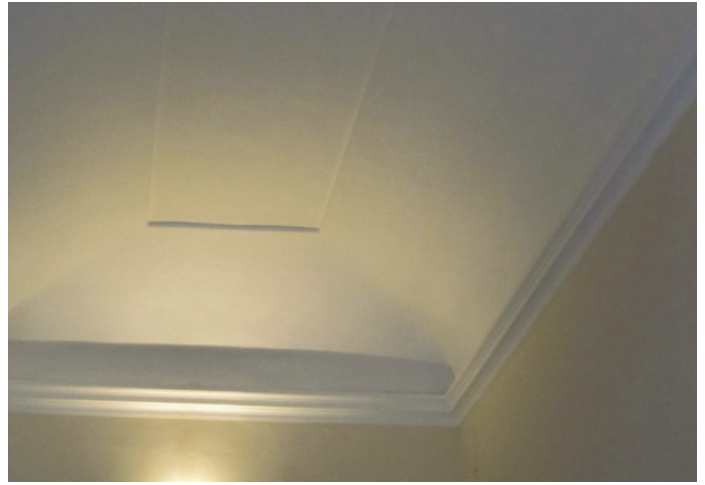

(a)

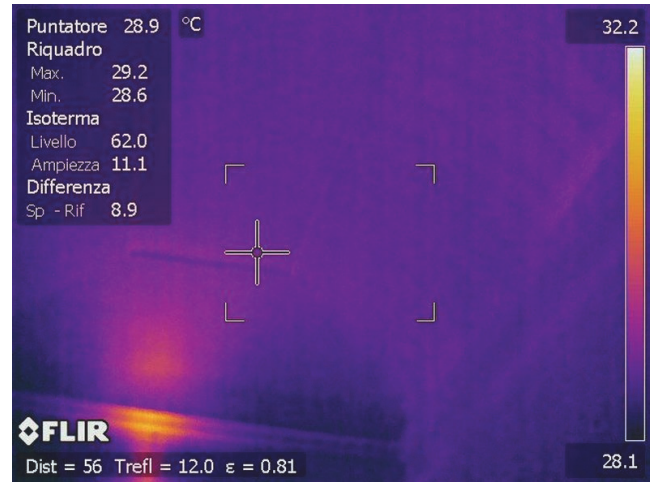

(b)

Figure 6: Room 48: (a) view and (b) thermographic image of the intrados of the vault.

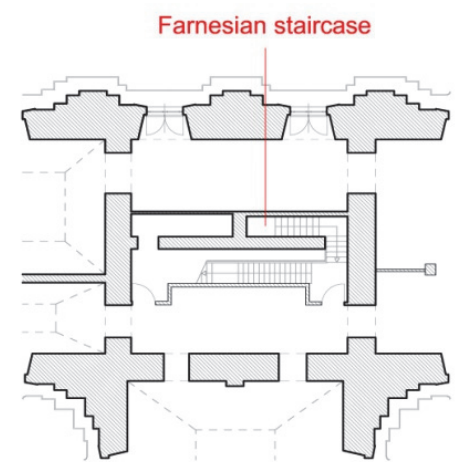

(a)

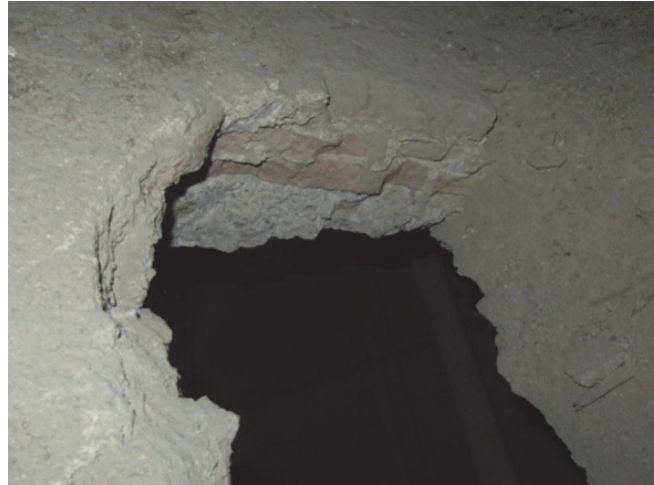

(b)

Figure 7: (a) Planimetric identification of the Farnesian staircase and (b) no-load-bearing masonry vault visible from the staircase.

\section{TYPOLOGICAL CHARACTERIZATION OF THE HORIZONTAL STRUCTURES}

$\mathrm{T}$ he management of the instrumental findings together with the information derived from the visual inspections and the analysis of the documentary sources allowed achieving a complete characterization of the horizontal structures upon the first level of the Capodimonte Museum.

In particular, the application of the infrared thermography led to a first distinction between structural masonry vaults and no-load-bearing vaults. The first ones must withstand their self weight, the non-permanent structural loading and the variable loading; the no-load-bearing vaults, instead, must withstand only their self-weight, while the other loadings are transferred to distinct and separated horizontal structures. However, it should be highlighted that the infrared thermography only provided images related to the intrados surface of the vaults and hence it is not adequate to describe the separated load-bearing horizontal structures. 
Therefore, by critically integrating different sources of information, a proper classification of the no-load-bearing vaults was proposed on the basis of their constructive typology and of the overlying horizontal structures. This approach allowed defining a complete typological characterization of the horizontal structures present upon the first floor of the building. In fact, the following typologies can be identified (Fig. 8):

- Load-bearing masonry vault;

- No-load-bearing masonry vault with overlying load-bearing masonry vault;

- No-load-bearing masonry vault with overlying horizontal diaphragm;

- No-load-bearing vault composed of timber structure with overlying load-bearing masonry vault;

- No-load-bearing vault composed of timber structure with overlying horizontal diaphragm;

- No-load-bearing masonry vault with visible extrados;

- Horizontal diaphragm.

Load-bearing masonry vaults (Fig. 9) have a prevailing configuration as a schifo or mirror vault and maximum height of about $8.8 \mathrm{~m}$; moreover they are dated back to the construction of the building and characterize the rooms of the north and south sides. Their structural behaviour could be easily modelled through validated numerical methods [28-31].

No-load-bearing masonry vaults with overlaying load-bearing masonry vaults have been identified in some rooms of the west side overlooking the north and south courtyards. This solution is likely related to the need of dividing a large room, covered by a masonry vault, in two smaller rooms and is likely contemporary to the last phase of construction. As already shown in Fig. 7, this kind of no-load-bearing vault is built with bricks disposed on a sheet and has thickness of about $20 \mathrm{~cm}$. For some rooms, the documentation related to the interventions dated back to 1985 allowed identifying the presence of tie roads and validating in this way the hypothesis of structural vault overlaying the no-load-bearing one [7].
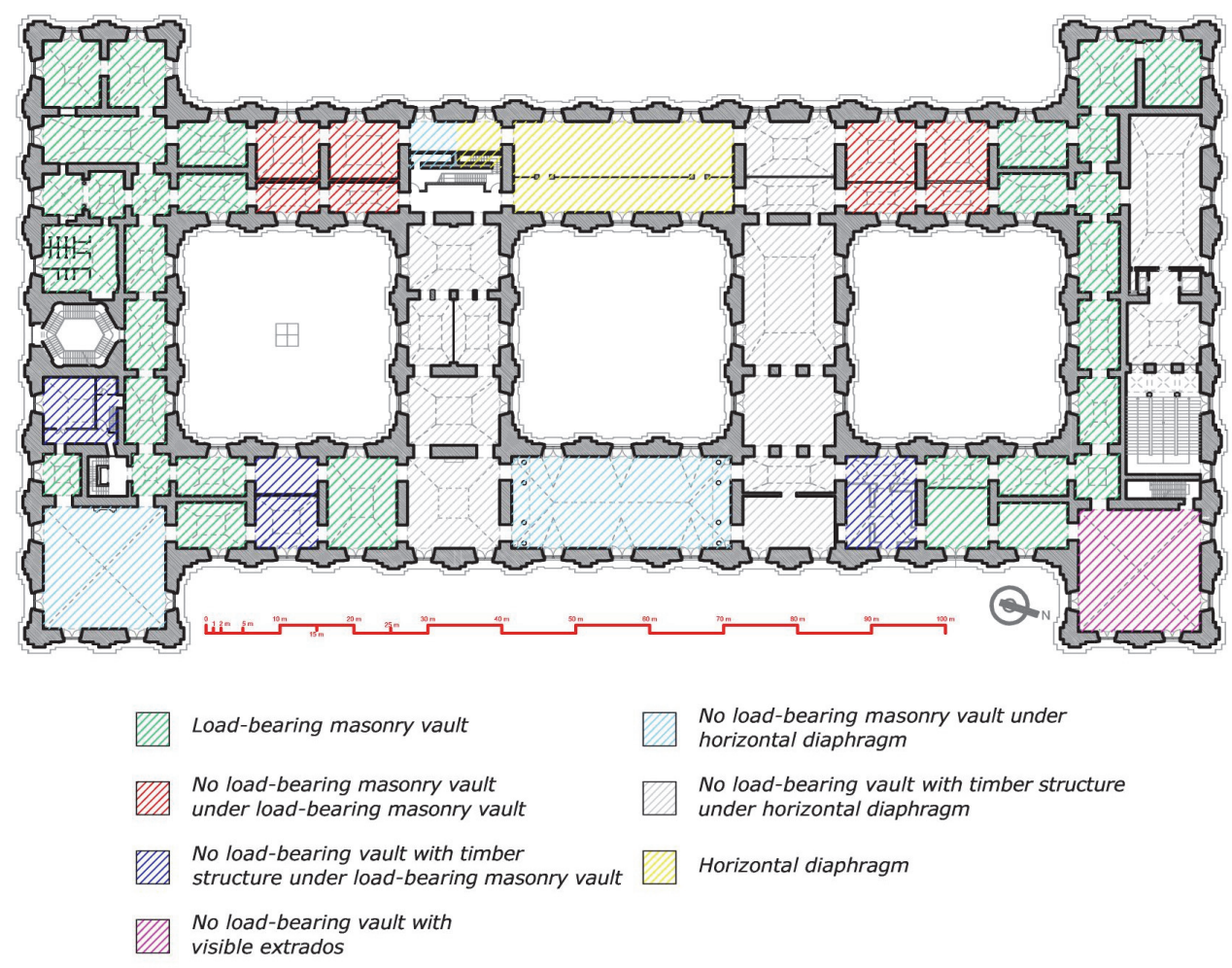

Figure 8: Typological characterization of the horizontal structures upon the first floor.

No-load-bearing masonry vaults with overlying horizontal diaphragms. The historic analysis allowed to refer this typology to two different circumstances: the first one is the substitution of the earlier load-bearing masonry vault with a c.a. diaphragm likely due to structural problems; the other one is related to the project of the architect De Felice of the years between 1952-1957, when new rooms devoted to the exposition were created on the last level of the building and horizontal structures were realized above the vaults of the rooms with double height upon the first level as the "Sala della Culla" (Figs. 2a and 10) and the "Salone delle Feste" (Fig. 2a) [7]. 
No-load-bearing vaults composed of timber structure with overlying load-bearing masonry vaults. Examples of this typology are the "Salottino di porcellana" (Fig. 3), the Library near the hexagonal staircase (Fig. 11) and the rooms on the east side of the south court. This typology dates back to the years between 1952 and 1957 [7] and is related to the need of dividing existing large rooms into two smaller ones, or in other cases it was adopted to host decorative furniture coming from other historic buildings.

No-load-bearing vaults composed of timber structures with overlying horizontal diaphragms were built to obtain vaulted intrados surfaces similar to their adjacent rooms. This typology mainly characterizes the rooms located in the transversal wings bordering the central court. Examples of this typology are also the vaults of the rooms as "Sala Tiziano" (Fig. 4), "Sala Collezione De Ciccio" (rooms 38-41 in Fig. 2a) and "Sala Armeria" (rooms 46 and 47 in Fig. 2a).

A single example of no-load-bearing masonry vault with visible extrados is represented by the vault of the "Sala Camuccini" (Fig. 12), a double height room located at the northeastern corner, opposite to the "Sala della culla". The extrados of this vault is visible from the crawl space where the presence of c.a. beams suggests the intention to realize an overlaying diaphragm as it was for the aforementioned "Sala della culla".
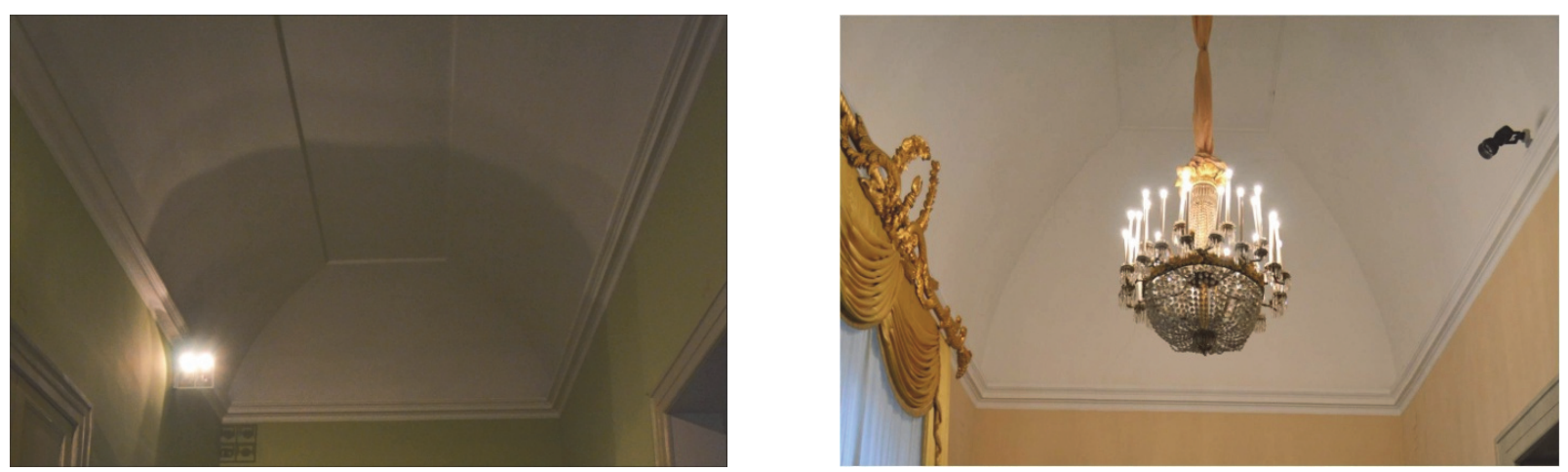

Figure 9: Load-bearing masonry vaults.
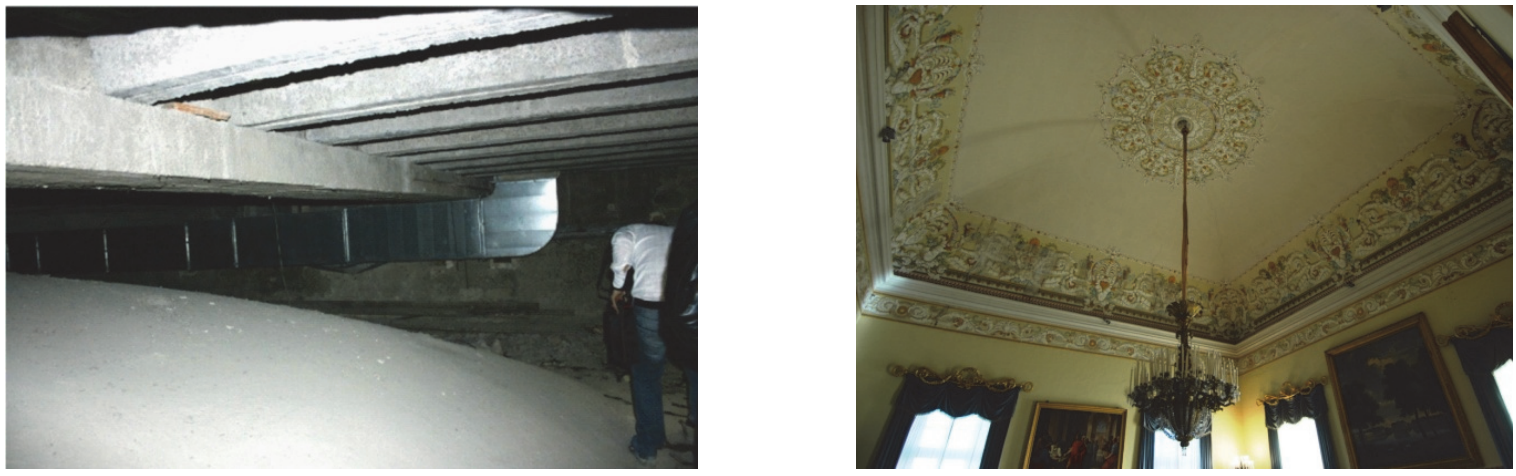

Figure 10: No-load-bearing masonry vaults with overlying horizontal diaphragm: the "Sala della culla".

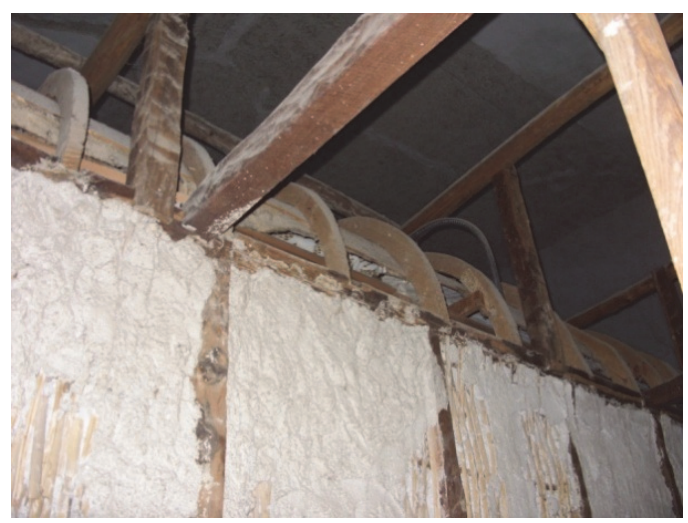

Figure 11: No-load-bearing masonry vault composed of timber skeleton visible from the Library. 


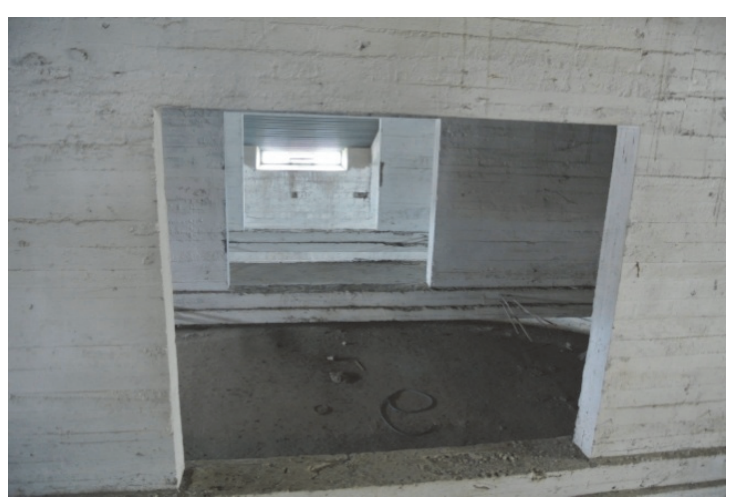

Figure 12: The extrados of the vault of the "Sala Camuccini".

\section{CONCLUSIONS}

A methodological project aimed at the assessment of the seismic safety of a building of historical and architectonic value cannot ignore the importance of the in-depth knowledge of the building itself. The knowledge acquisition phase consists of multiple investigations into an equally numerous number of fields.

This paper presents some aspects of the investigation campaign carried out by the authors in the framework of the Italian ARCUS-MiBACT Project on the "Assessment of the seismic safety of National Museums of Italy" supported by the Ministry of the Cultural Heritage (MiBACT). In particular, the management of multi-source information presented here was aimed at identifying the typology of the vaulted and horizontal structures upon the first level of the Capodimonte Museum located in Naples (Italy).

Generally, the use of analytical instruments of varying nature, compatible for use with a building of value, is a professional practice that strives to bring to the light both the characteristics of the building and issues affecting it. These instruments can also shed new light on methodological approaches to adopt to gain a better understanding of the construction, highlighting the need for the planner to gain a full understanding of the characteristics of the place before intervening, with respect to the building's identity.

In this line, the use of the thermography integrated with other sources of information, such as visual inspections, architectural survey, historic analysis and hypotheses of critical interpretation, resulted to be very useful for the chosen case study. In fact, the thermographic images of the intrados surfaces of the analyzed vaulted structures allowed a first distinction between structural masonry vaults and no-load-bearing vaults. For the latter category, two constructive typologies were recognized, as timber and masonry vaults. They are characterized by the presence of overlying horizontal structures, which have to fulfil the bearing function. In order to properly identify the features of these horizontal structures, instrumental investigations were then critically interpreted and integrated with other information derived from the visual inspections and the critical analysis of the documentary sources.

The presented methodological approach allowed achieving a complete characterization of the horizontal structures upon the first level of the Capodimonte Museum in Naples, but it can be recognized as easily extendable to any historical building of international interest. It actually represents a basic requirement to define a reliable model of the structural behaviour of the building aimed at the evaluation of its structural configuration and its seismic safety.

\section{ACKNOWLEDGEMENTS}

he authors acknowledge the sponsorship of Italian MiBACT through the ARCUS Project on the "Assessment of the seismic safety of National Museums of Italy" (2014-2015). The authors also wish to thank the Stress-scarl district that performed the diagnostic campaign and Professor G. Manfredi for his scientific and logistic support.

\section{REFERENCES}

[1] DCCM (2011). Directive of the Chairman of the Council of Ministers, Seismic risk evaluation and reduction of the cultural heritage, referred to the Technical Rules for Constructions NTC08, Official Gazette of the Italian Republic no. 47, February 26. (in Italian) 
[2] Lagomarsino, S. and Cattari, S. (2015). PERPETUATE guidelines for seismic performance-based assessment of cultural heritage masonry structures, B. Earthq. Eng., 13(1), pp. 13-47. DOI: 10.1007/s10518-014-9674-1

[3] Cantini, L., Bonavita, A., Parisi, M.A. and Tardini, C. (2016). Historical analysis and diagnostic investigations in the knowledge acquisition path for architectural heritage, Proc. 10 $0^{\text {th }}$ International Conference on Structural Analysis of Historical Constructions (SAHC 2016), Leuven (Belgium), pp. 166-172.

[4] Casapulla, C., Argiento, L.U., Frascadore, R., Maione, A., Prota, A. and Manfredi, G. (2015). Museo di Capodimonte. Report of the ARCUS-MIBACT Project on the "Assessment of the seismic safety of National Museums of Italy". Application of O.P.C.M. 3274/2003 s.m.i. and of the Directive P.C.M. 12.10.2007”. (in Italian)

[5] Casapulla, C., Maione, A. and Argiento, L.U. (2017). Seismic analysis of an existing masonry building according to the multi-level approach of the Italian guidelines on Cultural Heritage, Ing. Sismica-Ital., 34(1), pp. 40-59.

[6] Casapulla, C., Argiento, L.U. and Maione, A. (2018). Seismic safety assessment of a masonry building according to Italian Guidelines on Cultural Heritage: simplified mechanical-based approach and pushover analysis, B. Earthq. Eng., 16(7), pp. 2809-2837. DOI: 10.1007/s10518-017-0281-9

[7] Molajoli B. (1961). Il Museo di Capodimonte, Di Mauro Editore, Cava dei Tirreni (SA). (in Italian)

[8] Casapulla, C. and Argiento, L.U. (2016). The comparative role of friction in local out-of-plane mechanisms of masonry buildings. Pushover analysis and experimental investigation, Eng. Struct., 126, pp. 158-173. DOI: $10.1016 /$ j.engstruct.2016.07.036.

[9] Casapulla, C., Giresini, L. and Lourenço, P.B. (2017). Rocking and kinematic approaches for rigid block analysis of masonry walls: state of the art and recent developments, Buildings, 7(3), art. no. 69.

DOI: $10.3 \mathrm{~d} 390 /$ buildings 7030069.

[10] Cannizzaro, F., Pantò, B., Lepidi, M., Caddemi, S. and Caliò, I. (2017). Multi-directional seismic assessment of historical masonry buildings by means of macro-element modelling: application to a building damaged during the L'Aquila earthquake (Italy), Buildings, 7(4), art. no. 106. DOI: 10.3390/buildings7040106.

[11] Casapulla, C. and Argiento, L.U. (2018). In-plane frictional resistances in dry block masonry walls and rocking-sliding failure modes revisited and experimentally validated, Compos. Part B-Eng., 132, pp. 197-213.

DOI: 10.1016/j.compositesb.2017.09.013.

[12] Solarino, F., Giresini, L., Chang, W.S. and Huang, H. (2017). Experimental tests on a dowel-type timber connection and validation of numerical models, Buildings, 7(4), art. no. 116. DOI: 10.3390/buildings7040116.

[13] Sassu, M., Giresini, L., Bonannini, E. and Puppio, M.L. (2016). On the use of vibro-compressed units with bio-natural aggregate, Buildings, 6(3), art. no. 40. DOI: 10.3390/buildings6030040.

[14] Sassu, M., Stochino, F. and Mistretta, F. (2017). Assessment method for combined structural and energy retrofitting in masonry buildings, Buildings, 7(3), art. no. 71. DOI: 10.3390/buildings 7030071.

[15] Binda L. and Saisi A. (2009). Application of NDTs to the diagnosis of historic structures, Proc. of 7 th International Symposium on Non-Destructive Testing in Civil Engineering (NDTCE'09), Nantes (France), pp. 1-27.

[16] Carlomagno, G.M., Maio, R., Meola, C. and Roberti, N. (2005). Infrared thermography and geophysical techniques in cultural heritage conservation, Quant. Infr. Therm. J., 2(1), pp. 5-24. DOI: 10.3166/qirt.2.5-24.

[17] Grinzato, E., Bison, P.G. and Marinetti, S. (2002). Monitoring of ancient buildings by the thermal method, J. Cult. Herit., 3(1), pp. 21-29. DOI: 10.1016/S1296-2074(02)01159-7.

[18] Mercuri, F., Zammit, U., Orazi, N., Paoloni, S., Marinelli, M. and Scudieri, F. (2011). Active infrared thermography applied to the investigation of art and historic artefacts, J. Therm. Anal. Calorim., 104(2), pp. 475-485. DOI: $10.1007 /$ s10973-011-1450-8.

[19] Conde, B., Ramos, L.F., Oliveira, D.V., Riveiro, B. and Solla, M. (2017). Structural assessment of masonry arch bridges by combination of non-destructive testing techniques and three-dimensional numerical modelling: Application to Vilanova bridge, Eng. Struct., 148, pp. 621-638. DOI: 10.1016/j.engstruct.2017.07.011.

[20] Arce, A., Ramos, L.F., Fernandes, F.M., Sánchez-Aparicio, L.J. and Lourenço, P.B. (2018). Integrated structural safety analysis of San Francisco Master Gate in the Fortress of Almeida, Int. J. Archit. Herit., pp. 1-18. DOI: $10.1080 / 15583058.2017 .1370507$.

[21] Avdelidis, N.P. and Moropoulou, A. (2004). Applications of infrared thermography for the investigation of historic structures, J. Cult. Herit., 5(1), pp.119-127. DOI: 10.1016/j.culher.2003.07.002

[22] Meola, C. (2007). Infrared thermography of masonry structures, Infrared Phys. Techn., 49(3), pp. $228-233$. DOI: $10.1016 /$ j.infrared.2006.06.010.

[23] Spodek, J. and Rosina, E. (2009). Application of infrared thermography to historic building investigation, J. Archit. Conserv., 15(1), pp. 65-81. DOI: 10.1080/13556207.2009.107850401. 
[24] Maierhofer, C. and Roellig, M. (2009). Active thermography for the characterization of surfaces and interfaces of historic masonry structures, Proc. $7^{\text {th }}$ International Symposium on Non-Destructive Testing in Civil Engineering (NDTCE'09), Nantes (France), pp. 1-6.

[25] Cantini, L., Tedeschi, C., Tiraboschi, C. and Binda, L. (2013). Use of thermovision for the survey of a timber vault in Torino, In: Güneş O., Akkaya Y. (eds) Non-destructive Testing of Materials and Structures. RILEM Bookseries, vol 6, Dordrecht, Springer, pp. 1203-1208.

[26] Herschel, W. (1800). Experiments on the refrangibility of the invisible rays of the sun, Philos. T. R. Soc. Lond., 90, pp. 284-292. DOI:10.1098/rstl.1800.0015.JSTOR107057.

[27] Maldague, X.P.V. (2001). Theory and practice of infrared technology for nondestructive testing. J. Wiley Interscience, New York. ISBN: 978-0-471-18190-3.

[28] Caddemi, S., Caliò, I., Cannizzaro, F., Occhipinti, G. and Pantò, B. (2015). A parsimonious discrete model for the seismic assessment of monumental structures, Proc. of $15^{\text {th }}$ International Conference on Civil, Structural and Environmental Engineering Computing (Civil-Comp Press), Stirlingshire, UK, paper 82. DOI: 10.4203/ccp.108.82.

[29] Giresini, L., Sassu, M., Butenweg, C., Alecci, V. and De Stefano, M.D. (2017). Vault macro-element with equivalent trusses in global seismic analyses, Earthq. Struct., 12(4), pp. 409-423. DOI: 10.12989/eas.2017.12.4.409.

[30] Pantò, B., Cannizzaro, F., Caddemi, S., Caliò, I., Chácara, C. and Lourenço, P.B. (2017). Nonlinear modelling of curved masonry structures after seismic retrofit through FRP reinforcing, Buildings, 7(3), art. no. 79. DOI: $10.3390 /$ buildings 7030079 .

[31] Mousavian, E. and Mehdizadeh Saradj, F. (2018). Automated detailing and stability analysis of under-construction masonry vaults, J. Archit. Eng. ASCE 24(3), art. no. 04018014. DOI: 10.1061/(ASCE)AE.1943-5568.0000314. 